\title{
Genome-Wide Mapping of Adult Plant Resistance to Leaf Rust and Stripe Rust in CIMMYT Wheat Line Arableu\#1
}

\author{
Chan Yuan, ${ }^{1}$ Ravi P. Singh, ${ }^{2}$ Demei Liu, ${ }^{3}$ Mandeep S. Randhawa, ${ }^{2}$ Julio Huerta-Espino, ${ }^{4}$ and Caixia Lan ${ }^{1, \dagger}$ \\ ${ }^{1}$ Huazhong Agricultural University, College of Plant Science \& Technology, Hongshan District, Wuhan, Hubei Province \\ 430070, People's Republic of China \\ ${ }^{2}$ International Maize and Wheat Improvement Center (CIMMYT), 06600 Mexico D.F., Mexico \\ ${ }^{3}$ Northwest Institute of Plateau Biology, Chinese Academy of Sciences and Qinghai Provincial Key Laboratory of Crop Molec- \\ ular Breeding, Xining 810008, People's Republic of China \\ ${ }^{4}$ Campo Experimental Valle de Mexico INIFAP, 56230 Chapingo, Edo. de Mexico, Mexico
}

\begin{abstract}
Leaf (brown) rust (LR) and stripe (yellow) rust (YR), caused by Puccinia triticina and $P$. striiformis f. sp. tritici, respectively, significantly reduce wheat production worldwide. Disease-resistant wheat varieties offer farmers one of the most effective ways to manage these diseases. The common wheat (Triticum aestivum L.) Arableu\#1, developed by the International Maize and Wheat Improvement Center and released as Deka in Ethiopia, shows susceptibility to both LR and YR at the seedling stage but a high level of adult plant resistance (APR) to the diseases in the field. We used $142 \mathrm{~F}_{5}$ recombinant inbred lines (RILs) derived from Apav\#1 $\times$ Arableu\#1 to identify quantitative trait loci (QTLs) for APR to LR and YR. A total of 4,298 genotyping-by-sequencing markers were used to

Lr46/Yr29, a known pleiotropic resistance gene. QLr.cim-1BL.2 and QYr.cim-1BL.2 were also located on wheat chromosome $1 \mathrm{BL}$ at $37 \mathrm{cM}$ from $L r 46 / Y r 29$ and may represent a new segment for pleiotropic resistance to both rusts. $Q L$ r.cim-7BL is likely $L r 68$ given its association with the tightly linked molecular marker $c s 7 B L N L R R$. In addition, QLr.cim3DS, QYr.cim-2AL, QYr.cim-4BL, QYr.cim-5AL, and QYr.cim-7DS are probably new resistance loci based on comparisons with published QTLs for resistance to LR and YR. Our results showed the diversity of minor resistance QTLs in Arableu\#1 and their role in conferring nearimmune levels of APR to both LR and YR, when combined with the pleiotropic APR gene $L r 46 / Y r 29$.
\end{abstract} construct a genetic linkage map. The study identified four LR resistance QTLs and six YR resistance QTLs in the population. Among these, QLr.cim-1BL.1/QYr.cim-1BL.1 was located in the same location as
Keywords: adult plant resistance, genome-wide mapping, leaf rust, quantitative trait loci, stripe rust, wheat, wheat rust
Leaf (brown) rust (LR) and stripe (yellow) rust (YR), caused by the airborne fungi Puccinia triticina Erikss. (Pt) and P. striiformis Westend. f. sp. tritici Erikss. (Pst), respectively, significantly reduce wheat production worldwide (Todorovska et al. 2009). LR occurs wherever wheat is grown and develops rapidly in temperatures of 15 to $20^{\circ} \mathrm{C}$ and high humidity (Kolmer 1996). The $P t$ fungus can adapt to diverse climatic conditions and is hence the most widely distributed of all cereal rusts (Bolton et al. 2008). LR has caused yield losses of up to 50\% in wheat in Egypt (Draz et al. 2015). YR occurs widely where wheat is grown and $>80 \%$ of the world's wheat area is considered vulnerable (Dubin and Brennan 2009). The disease has sometimes been characterized as the most destructive cereal rust (Beddow et al. 2015) and a major threat to global food security. Although fungicides can be used for controlling wheat rusts (Joshi et al. 2017), their use is costly and not environmentally friendly in the long term. In contrast, planting resistant cultivars is an economically and environmentally effective approach to control these diseases.

Genetic resistance to rusts in wheat falls into two broad categories. Seedling resistance, also called all-stage resistance (ASR) because of

${ }^{\dagger}$ Corresponding author: C. X. Lan; cxlan@mail.hzau.edu.cn

Funding: This work was supported by the Australian Grains Research and Development Corporation, with funding from the Australian Cereal Rust Control Program, the CGIAR Research Program on WHEAT (WHEAT), the International Cooperation and Exchange of the National Natural Science Foundation of China (grant number 31861143010), the Huazhong Agricultural University Scientific \& Technological Self-Innovation Foundation, and the Open Project of Qinghai Provincial Key Laboratory of Crop Molecular Breeding (grant 2017-ZJ-Y14).

The author(s) declare no conflict of interest.

Accepted for publication 7 December 2019.

(C) 2020 The American Phytopathological Society its effectiveness throughout the growth stages of the crop, typically shows race specificity and can confer moderate-to-high protection depending on the resistance gene in wheat and avirulence status in the pathogen. Adult plant resistance (APR) is often expressed during postseedling growth stages and is based on race nonspecific resistance genes that individually tend to provide only small-tointermediate resistance; APR is more durable than ASR as a result of its race nonspecific nature (Chen 2005; Lan et al. 2017; Rinaldo et al. 2017).

Most known rust resistance genes originated from bread wheat or wild species related to wheat (Ahmed et al. 2014; Suchismita et al. 2016). About 80 resistance genes to LR and YR each have been permanently named in wheat and localized on specific wheat chromosomes (Kthiri et al. 2018; McIntosh et al. 2017; Sapkota et al. 2019). In addition, more than 200 LR resistance quantitative trait loci (QTLs) and 300 YR resistance QTLs have been identified in various wheat varieties, some of which may be the same ones but present in diverse genetic backgrounds (Pinto da Silva et al. 2018; Wang and Chen 2017). Among the above, only three genes (Lr34/Yr18/Sr57/ Pm38, Lr46/Yr29/Sr58/Pm39, and Lr67/Yr46/Sr55/Pm46) have been found conferring pleiotropic APR to LR, YR, stem rust (SR), and powdery mildew diseases, respectively. Combining these pleiotropic APR genes with other minor QTLs/genes in wheat has been shown to significantly improve the plant disease resistance (W. Li et al. 2018b). Interactions between pathogen avirulence and host plant resistance genes are complex as rust fungi readily mutate and overcome resistance genes (Dubin and Brennan 2009; Feng et al. 2018; Kolmer 2013; Wang et al. 2018). Identifying new, durable sources of resistance against wheat rusts remains a global priority.

High-density molecular mapping offers a powerful tool to identify and analyze QTLs associated with traits of interest in crop species, enabling a better understanding of the genetic architecture of complex traits that can be applied to predict breeding values (Poland et al. 2012a; Tian et al. 2015). The massive and complex genomes of wheat have initially constrained whole-genome sequencing, but 
next-generation technologies now allow high-throughput, sequencebased genotyping, the generation of high-density, genome-wide markers at a relatively low cost (Baird et al. 2008). Genotypingby-sequencing (GBS) using restriction enzymes to reduce targeted complexity has been followed by multiple sequencing to produce high-quality polymorphic data (Mascher et al. 2013; Poland and Rife 2012), resulting in thousands of molecular markers even without a reference genome sequence or previous polymorphism discovery (Poland et al. 2012b). GBS has been successfully applied in large genome crops, such as wheat (Triticum aestivum L.) and barley (Hordeum vulgare L.), to develop new molecular markers (Poland et al. 2012a). Elbasyoni et al. (2018) validated that GBS-scored single nucleotide polymorphisms (SNPs) are comparable to or better than array-scored SNPs in the application of genomic prediction. Another 2018 study used GBS markers to construct genetic maps in wheat, confirming the value of this genotyping platform in mapping known and new YR APR loci and in identifying the corresponding closely linked markers (Q. Li et al. 2018a). GBS has been shown to be a simple but robust method for association studies and genomeassisted breeding and for mapping rust resistance loci (Elshire et al. 2011).

The purposes of our study were as follows: (i) to analyze the genetic bases of LR and YR resistance using an $\mathrm{F}_{5}$ recombinant inbred line (RIL) population produced by the cross of wheat lines Apav\#1 and Arableu\#1, (ii) to identify APR loci that confer resistance to both rusts, and (iii) to determine the role of individual resistance loci and their interactions in conferring APR.

\section{Materials and Methods}

Parental materials. We used $142 \mathrm{~F}_{5}$ RILs developed from the cross between spring wheat lines Apav\#1 and Arableu\#1 (referred to hereafter as Ableu\#1) in the study. Apav\#1 (GID 1853706), a RIL derived from the Avocet- $\mathrm{YrA} \times$ Pavon 76 cross, was susceptible to LR and YR at all growth stages. The pedigree of Ableu\#1 (GID 7210108) is Attila/3*Bacanora*2//Baviacora92/3/Kiritati/Weebil\#1/ 4/Danphe. Ableu\#1 was represented by a single spike taken for genetic analysis from the variety Deka, released in Ethiopia during 2018. Deka shows good resistance to stripe rust and SR both in Ethiopia and Kenya; one of its parents is Danphe, released as Danda'a in Ethiopia and widely grown for the last decade in the Ethiopian highlands, where it has shown durable resistance to both SR and YR. Ableu\#1 is susceptible to LR and YR at the seedling stage but is highly resistant to both rusts at the adult plant stage. Three spikes of Apav\#1 were used for crossing with Ableu\#1, $F_{1}$ seeds were sown $10 \mathrm{~cm}$ apart, and three $F_{1}$ plants were harvested individually. The RIL population was developed through bulk advancement to $F_{4}$ by growing 200 plants $10 \mathrm{~cm}$ apart from each of the three $F_{1}$ plants. One spike of each plant was harvested and bulked at $F_{2}$ and
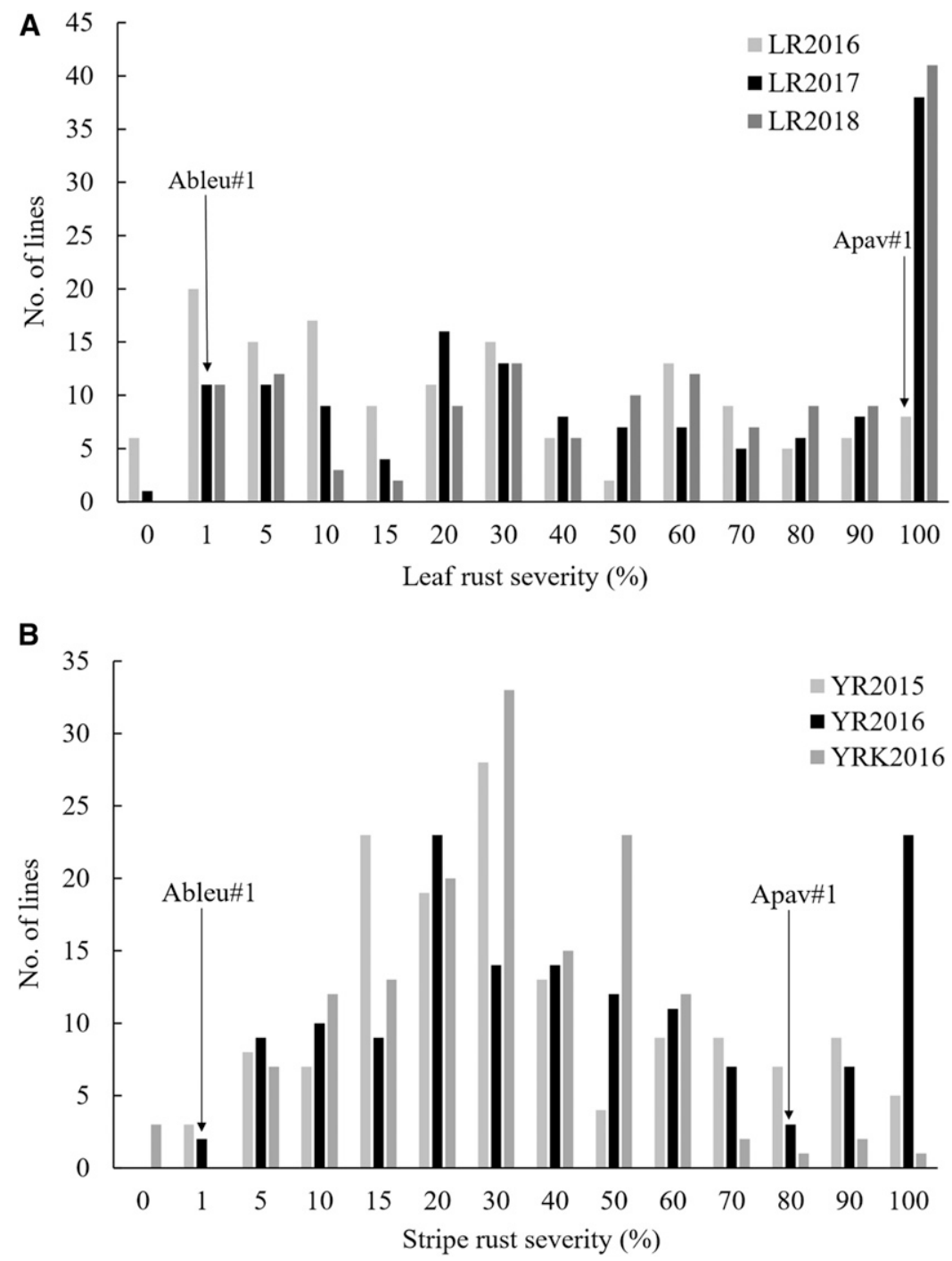

Fig. 1. A, Frequency distributions for final disease severity (FDS) of leaf rust for $142 \mathrm{Apav \# 1} \times$ Ableu\#1 $\mathrm{F}_{5}$ recombinant inbred lines in field trials at Ciudad Obregón, Mexico, during 2015 to 2016 (LR2016), 2016 to 2017 (LR2017), and 2017 to 2018 (LR2018). B, FDS for stripe rust at Toluca, Mexico, during 2015 (YR2015) and 2016 (YR2016) and at Njoro, Kenya, during 2016 (YRK2016). 
$\mathrm{F}_{3}$. In the $\mathrm{F}_{4}$ generation, about 75 individual plants were harvested from two $\mathrm{F}_{4}$ families to obtain the $\mathrm{F}_{5}$ RIL population. Seed from each plant was multiplied, and the same seed source was used for phenotypic evaluation and genotypic analysis. During population advancement, fungicide was used to keep the plants free from diseases and ensure the genotypic representation of each generation through randomly harvested spikes.

Field trials. The $\mathrm{F}_{5}$ RIL population and their parents were evaluated for APR to LR at the CENEB Research Station in Ciudad Obregón, Mexico, during the 2015 to 2016, 2016 to 2017, and 2017 to 2018 growing seasons, referred to hereafter as the LR2016, LR2017, and LR2018 experiments, respectively. YR phenotyping was conducted for two seasons (2015 and 2016) at the International Maize and Wheat Improvement Center (CIMMYT) Research Station near Toluca, Mexico, and for one season (2016) in Njoro, Kenya, referred to hereafter as the YR2015, YR2016, and YRK2016 experiments, respectively. The field plots were divided into $0.7-\mathrm{m}$ paired rows, and about 60 plants of each RIL were grown per row. Susceptible spreader plants were grown on hills around each test site with a separation of $0.3 \mathrm{~m}$. For the LR experiments, the Yr24- and Yr26-carrying Avocet near-isolines and Morocco were used as the susceptible spreaders, and $P t$ race MBJ/SP was used to inoculate the spreaders at the jointing growth stage (around 2 months after planting). Each spreader was sprayed with Soltrol 170 oil suspended with rust urediniospores. $P t$ race MBJ/ SP has the following avirulence/virulence formula: $\operatorname{Lr} 2 a, 2 b, 2 c$, $3 \mathrm{ka}, 9,16,19,21,24,25,(26), 28,29,30,32,33,36 / 1,3,3 \mathrm{bg}$, $10,11,12,13,14 a, 14 b, 15,17 a, 18,20,23,27+31$ (HerreraFoessel et al. 2012). For the YR experiments, the near-isoline of Avocet containing gene $\mathrm{Yr} 31$ was mixed with Morocco and six lines developed from an Avocet $\times$ Attila cross in equal proportions and used as the spreader. Inoculation was carried out with $P s t$ isolate Mex14.141 at the early jointing growth stage (around 1.5 months after planting). The avirulence/virulence formula of the $P s t$ isolate is Yr1, 4, 5, 10, 15, (17), 24, Sp/ 2, 3, 6, 7, 8, 9, 27, 31, A (HuertaEspino and Singh 2017). The inoculation method was similar to that used for LR (Lan et al. 2014).

Disease severities (DSs) for the 142 RILs and their parents in each environment were recorded twice or thrice following the modified Cobb's scale (Peterson et al. 1948). The host reaction to infection was determined in the manner described by Roelfs et al. (1992), where $\mathrm{R}$ indicates resistance (the leaf without any uredinia but with necrotic or chlorotic tissues), MR indicates moderate resistance (the leaf with the same uredinia and surrounded by the necrotic or chlorotic tissues), MS indicates moderately susceptible (moderate-sized uredinia without necrotic or chlorotic tissues), and $\mathrm{S}$ indicates susceptible (large uredinia without necrotic or chlorotic tissues). We took the first notes when the susceptible check Apav\#1 showed approximately $80 \%$ DS, the second notes about a week later when the DS of susceptible check reached 90 to $100 \%$, and a final note about a week later. The method of Bjarko and Line (1988) was used to calculate the area under the disease progress curve (AUDPC). The AUDPC scores and the final disease severity (FDS) were applied in the genetic analysis.

Correlation analysis of the phenotypic data. SAS 9.2 software (SAS Institute, Cary, NC) was used to calculate the correlations of LR and YR FDS values for each season. The $t$ test was used to

Table 1. Phenotypic Pearson's correlations for leaf rust (Ciudad Obregón, Mexico: LR2016, LR2017, and LR2018) and stripe rust (Toluca, Mexico: YR2015 and YR2016; and Njoro, Kenya: YRK2016) in the 142 Apav\#1 $\times$ Ableu\# $1 F_{5}$ recombinant inbred line population using the final disease score for each season ${ }^{z}$

\begin{tabular}{lccccc}
\hline Environment & YR2015 & YR2016 & YRK2016 & LR2016 & LR2017 \\
\hline YR2016 & $0.91^{*}$ & & & & \\
YRK2016 & $0.81^{*}$ & $0.83^{*}$ & & & \\
LR2016 & $0.64^{*}$ & $0.67^{*}$ & $0.68^{*}$ & & \\
LR2017 & $0.74^{*}$ & $0.75^{*}$ & $0.75^{*}$ & $0.82^{*}$ & \\
LR2018 & $0.72 *$ & $0.74^{*}$ & $0.70^{*}$ & $0.81^{*}$ & $0.91^{*}$ \\
\hline
\end{tabular}

${ }^{\mathrm{z}}$ The asterisk indicates significant at $P<0.0001$. assess the significance of interaction effect for pairwise comparisons of both LR and YR resistance QTLs with the FDS values in each environment.

Genetic linkage map construction and QTL mapping. DNA was extracted from about 20 plants of each line and parents using the cetyl trimethylammonium bromide method (Dreisigacker et al. 2016). The DArT-GBS genotyping platform based at the CIMMYT headquarters, which utilizes high-throughput genotyping developed by Diversity Arrays Technology (DArT) (https://www.diversityarrays. com), was used to genotype the parents and RIL population. A total of 73,182 presence/absence variation (PAV) markers and 75,854 SNP markers were obtained, of which 2,348 PAV markers and 2,660 SNP markers were selected to make linkage groups by removing markers of distorted segregation $(P<0.001)$, monomorphic markers, and markers with $>30 \%$ missing data. Genetic linkage groups were established using Joinmap 4.1 (Van Ooijen 2006) with a logarithm of odds (LOD) threshold of 5.0. MapChart (Voorrips 2002) was used to draw genetic linkage maps. IciMapping 4.1 software (Meng et al. 2015) was used to detect FDS-related QTLs in each environment, AUDPC, and mean of final disease severity (MFDS) across the 3 years for each rust to obtain the QTL position, LOD scores, phenotypic variance explained (PVE), and the additive effect of each locus. One-thousand permutations were used to calculate LOD scores for each trait and to declare significant QTLs at $P<0.05$.

The physical positions of two QTLs on chromosome arm 1BL were compared with those previously reported on the same chromosome arm in various wheat lines, including Oligoculm (Suenaga et al. 2003), Pavon 76 (Mateos-Hernandez et al. 2006; William et al. 2006), Pastor (Rosewarne et al. 2012), Francolin\#1 (Lan et al. 2014), and Chilero (Ponce-Molina et al. 2018), based on the Chinese Spring reference genome map published by the International Wheat Genome Sequencing Consortium (2014, 2018). Software MapGene2Chrom web version 2.1 (http://mg2c.iask.in/mg2c_v2.1/) was used to draw the relative physical map positions based on the flanking molecular markers identified in each study.

\section{Results}

Wheat rust response in fields. The MFDS and reaction types to LR and YR of Apav\#1 and Ableu\#1 were $100 \mathrm{~S}$ (susceptible) and $1 \mathrm{MS}$ (moderately susceptible) and $80 \mathrm{~S}$ and $1 \mathrm{MS}$, respectively, at the adult plant stage in field trials. The frequency distributions of Apav\#1 $\times$ Ableu\#1 RILs for LR (Fig. 1A) and YR (Fig. 1B) were continuous, indicating the quantitative inheritance of APR to both rusts.

Correlation analysis. The LR severity correlation coefficient $(r)$ for Apav\#1 $\times$ Ableu\#1 RILs ranged from 0.81 to $0.91(P<$ $0.0001)$ among the three environments. The same correlation coefficient range of 0.81 to $0.91(P<0.0001)$ also occurred for YR over the 2 years at Toluca, Mexico, and 1 year at Njoro, Kenya (Table 1). In addition, the phenotypic coefficients between LR and YR resistance ranged from 0.64 to $0.75(P<0.0001)$ (Table 1$)$, indicating that some loci conferred resistance to both rusts.

Genetic linkage mapping. A genetic linkage map was constructed with a total of 4,298 markers and defined 41 linkage groups on 19 chromosomes. Chromosomes 4D and 5D did not have any linkage group, owing to the lack of polymorphic markers.

Four QTLs were detected for LR resistance QTLs, and the resistance alleles were all from the resistant parent Ableu\#1. Two QTLs were located on chromosome 1BL (QLr.cim-1BL.1 and QLr.cim1BL.2), one on 3DS (QLr.cim-3DS), and one on 7BL (QLr.cim7BL). The major QTL, QLr.cim-1BL.1, flanked by SNP markers 5411162|F|0-35:A>C-35:A>C and 1132278|F|0-20:C>T-20:C>T, was detected in all tested environments with PVE values ranging from 45.4 to $51.6 \%$ and LOD values from 33.3 to 37.1 (Fig. 2A; Table 2). This locus also showed a large effect for YR resistance over all three environments, with PVE values ranging from 25.8 to $31.7 \%$ (Fig. 2A; Table 2). QLr.cim-1BL.2 was closely linked to markers 1716123, 2303890, 2269974|F|0-24:G>A-24:G>A, 2253824|F|043:G>A-43:G>A, 100041322|F|0-38:A>G-38:A>G, and 100084210| $F \mid 0-16: A>G-16: A>G$. The most stable flanking markers were SNP

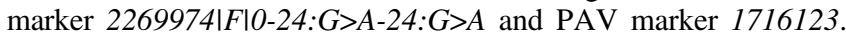


QLr.cim-1BL.2 accounted for 7.0 to $28.6 \%$ of the phenotypic variation for resistance to LR (Fig. 2B; Table 2). The third QTL, QLr.cim$7 B L$, was flanked by SNP marker $1033503|F| 0-6: A>G-6: A>G$ and PAV markers 1121184 and 1089497, with PVE values ranging from 13.7 to $31.3 \%$ (Fig. 2D; Table 2). The fourth QTL, QLr.cim-3DS, was detected in only two environments and was flanked by two PAV markers, 1233406 and 3941237 . It was associated with 2.2 to $4.0 \%$ of the phenotypic variation for LR resistance (Fig. 2C; Table 2).

Six YR resistance QTLs were detected on chromosomes 1BL, 2AL, 4BL, 5AL, and 7DS and designated as QYr.cim-1BL.1, QYr. cim-1BL.2, QYr.cim-2AL, QYr.cim-4BL, QYr.cim-5AL, and QYr. cim-7DS, respectively. $Q Y$ r.cim-1BL.1 was detected at the same location as QLr.cim-1BL.1 and accounted for 20.3 to $40.7 \%$ of the variation for YR severity on the RILs in three environments (Fig. 2A; Table 2). Another locus on 1BL, QYr.cim-1BL.2, was mapped at the same position as QLr.cim-1BL.2 and was associated with 10.4 to $39.0 \%$ of the phenotypic variation for YR resistance (Fig. 2B; Table 2). The third QTL, QYr.cim-4BL, accounted for 7.1 to
$10.6 \%$ of the phenotypic variation for YR resistance and was located in the interval of SNP markers $1235862|F| 0-42: C>T-42: C>T$ and 1220607|F|0-68:T>C-68:T>C (Fig. 2F; Table 2). The fourth QTL, QYr.cim-5AL, was flanked by SNP markers $1084162|F| 0-42: C>A$ 42:C $>A$ and 4911066|F|0-22:A>G-22:A>G and PAV marker 1131694 and accounted for 2.1 to $10.9 \%$ of the phenotypic variation in resistance to YR (Fig. 2G; Table 2). The resistance alleles at the above four QTLs were from Ableu\#1. In addition, the resistance alleles at two YR resistance loci, QYr.cim-2AL and QYr.cim-7DS, were contributed by the susceptible parent Apav\#1 and accounted for 4.2 and for 4.1 to $5.5 \%$ of the phenotypic variations, respectively, in response to YR (Fig. 2E and H; Table 2). QYr.cim-2AL was flanked by

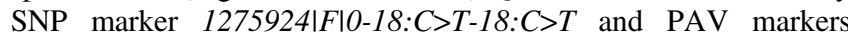
1117352 and 4989805. QYr.cim-7DS was flanked by SNP marker 987784|F|0-55:T>G-55:T>G and PAV marker 1117156.

Interactive effects. Based on the presence of four LR and six YR resistance QTLs, we divided the $\mathrm{F}_{5}$ RILs into 10 and 8 groups, respectively (Tables 3 and 4). The presence of parental alleles for each QTL was determined by the group referred to the corresponding
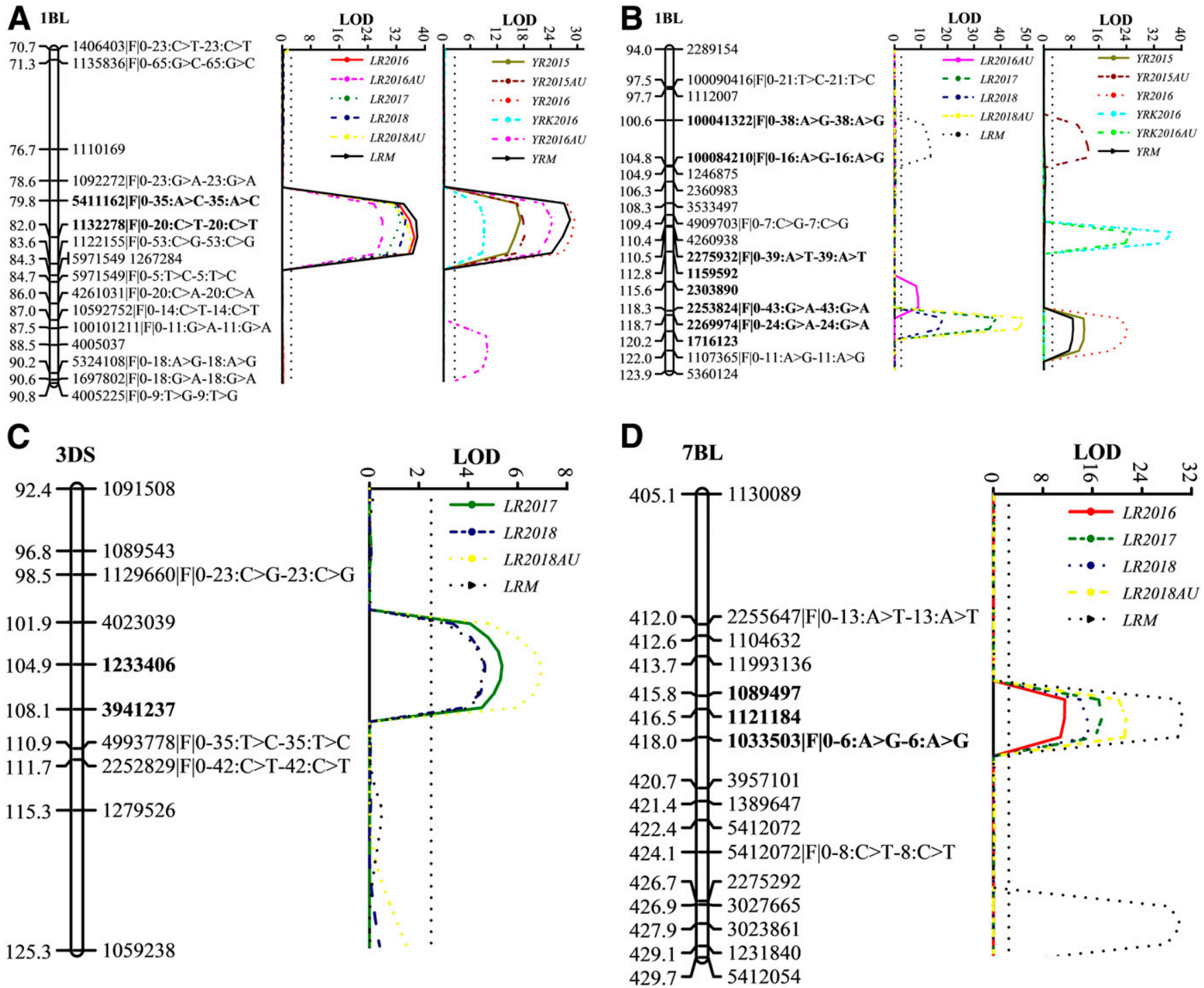

(Continued)

Fig. 2. Likelihood plots for quantitative trait loci for adult plant resistance to leaf rust on wheat chromosomes $A$ and $B, 1 B L, C, 3 D S$, and $D, 7 B L$ and to stripe rust on wheat chromosomes $\mathbf{A}$ and $\mathrm{B}, 1 \mathrm{BL}, \mathrm{E}, 2 \mathrm{AL}, \mathrm{F}, 4 \mathrm{BL}, \mathrm{G}, 5 \mathrm{AL}$, and $\mathrm{H}, 7 \mathrm{DS}$ identified using IciMapping 4.1 software in a population of 142 recombinant inbred lines from the cross Apav\#1 $\times$ Ableu\#1. Positions in centimorgans of the molecular markers along chromosomes are shown on the vertical axes using cumulated genetic distances. LOD $=$ logarithm of odds; LR2016, LR2017, and LR2018 = phenotypic data for leaf rust resistance recorded at Ciudad Obregón, Mexico, during 2015 to 2016, 2016 to 2017, and 2017 to 2018, respectively; LR2016AU and LR2018AU = area under the disease progress curve (AUDPC) at Ciudad Obregón during 2016 and 2018, respectively; YR2015 and YR2016 = phenotypic data for stripe rust resistance recorded at Toluca, Mexico, during 2015 and 2016, respectively; YRK2016 = phenotypic data for stripe rust resistance recorded at Njoro, Kenya, during 2016; YR2015AU, YR2016AU, and YRK2016AU = AUDPC at Toluca and Njoro during 2015 and 2016, respectively; and LRM and $\mathrm{YRM}=$ mean final disease severity over tested environments. 
flanking markers. The FDS of RILs ranged from 25.0 to $60.0 \%$ in all tested environments when QLr.cim-1BL.1 was present alone, whereas there was no significant difference between RILs carrying only $Q L$ r.cim-3DS and those without any locus, indicating only a minor effect of QLr.cim-3DS on LR resistance. The FDS of the population ranged from 43.9 to $76.5 \%$ when $Q L$ r.cim-7BL was present alone and from 65 to $75 \%$ when RILs carried only QLr.cim-1BL.2. In addition, the mean FDS for RILs ranged from 1.1 to $2.1 \%$ when they possessed all four LR resistance alleles, providing a nearimmune response (Table 3). Regarding YR resistance, neither QYr.cim-5AL nor $Q Y$ r.cim- $4 B L$ provided a significant reduction in FDS when either one was present alone, but the combination of these two QTLs reduced the FDS from $55.0-92.2 \%$ to $42.5-60.0 \%$, respectively (Table 4). Unfortunately, we did not find the RILs only carrying QYr.cim-1BL.1 or QYr.cim-1BL.2, but the FDS of RILs carrying both of them were significantly lower than those of RILs carrying QYr.cim-5AL and QYr.cim-4BL in combination. No significant difference was found between RILs with QYr.cim$1 B L .1+Q Y$ r.cim-1BL.2+QYr.cim- $4 B L$ from those with $Q Y r$. cim-1BL.1+QYr.cim-1BL.2+QYr.cim-5AL or RILs with all four resistance alleles.

\section{Discussion}

New molecular marker technology and genotyping platforms can help select varieties with target traits from large populations, improve selection efficiency, and, in particular, help to locate rust resistance genes/loci in wheat. Thus, over a hundred genes and QTLs for rust resistance have been reported and used to protect wheat against continually evolving virulence races (Mir et al. 2014). In our study, four and six resistance QTLs for LR and YR were detected, respectively, by using GBS molecular markers and phenotypic data for an Apav\#1 $\times$ Ableu\#1 RIL population.

Two colocated resistance loci, QLr.cim-1BL.1/QYr.cim-1BL.1 and QLr.cim-1BL.2/QYr.cim-1BL.2, on wheat chromosome 1BL showed the most significant resistance effect for both LR and YR. Several LR and YR resistance genes mapped on wheat chromosome 1BL have been reported, such as Lr33 (Dyck et al. 1987), Lr44 (Dyck and Sykes 1994), Lr46/Yr29 (William et al. 2003), Lr51 (Helguera et al. 2005), LrZH84 (Zhao et al. 2008), and Lr71 (Mohler et al. 2012). However, only resistance gene $L r 46 / Y r 29$ confers pleiotropic APR to both LR and YR. Lr46/Yr29 has conferred slow rusting resistance for more than 40 years (Singh et al. 1998). Lan et al. (2015) reported that the tall

Fig. 2. (Continued from previous page)
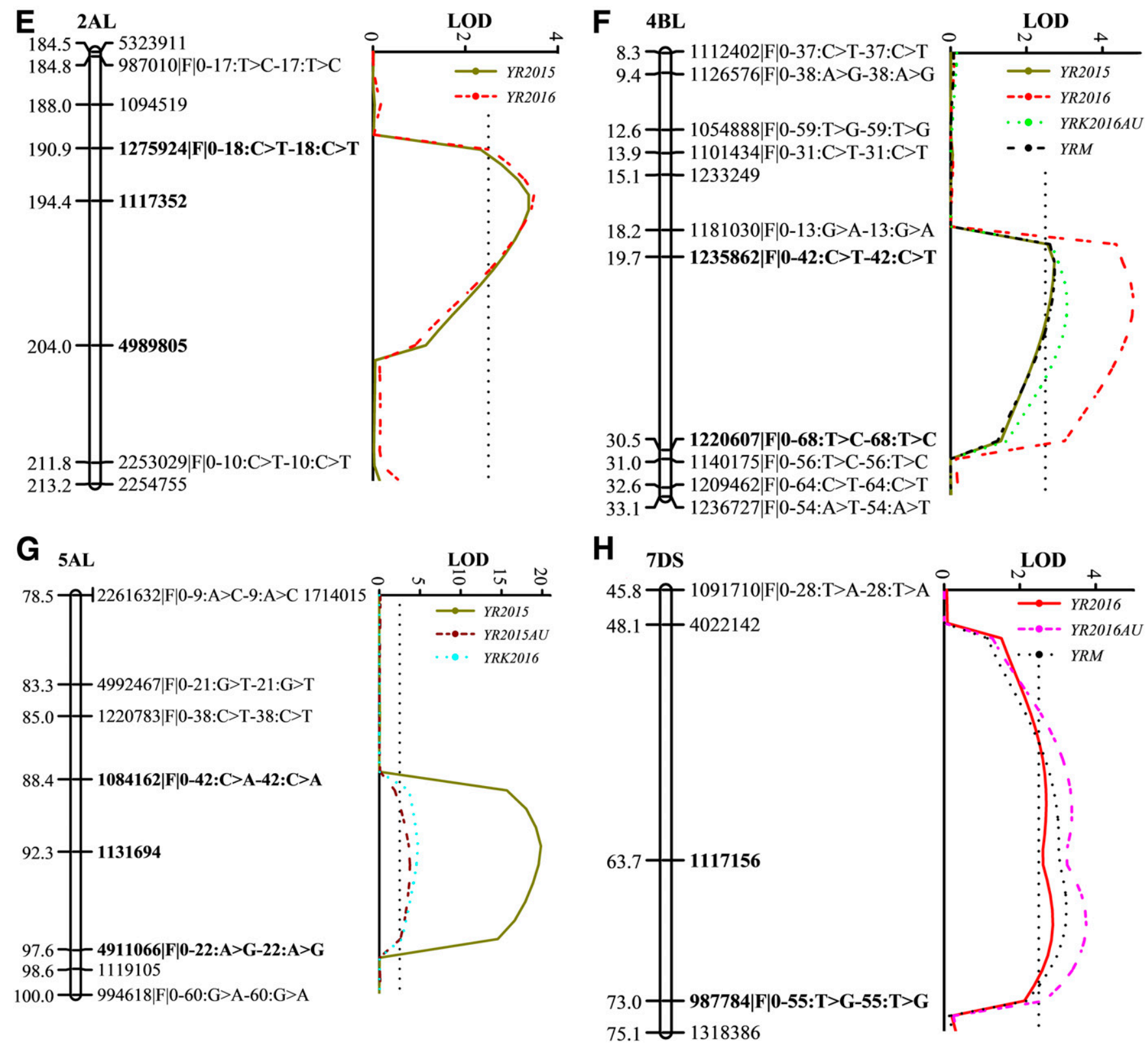
Indian variety Sujata showed LR DSs ranging between 7.4 and $16.5 \%$ and YR severities between 7.7 and $13.5 \%$ in Mexico when it combined pleiotropic APR genes Lr46/Yr29 and Lr67/Yr46.
Lr46/Yr29 was also detected in an $\mathrm{F}_{2: 3}$ population from the cross Fundulea $900 \times$ Thatcher, explaining 5.5 to $11.5 \%$ of the phenotypic variation in LR resistance over 2 years under a rust-prone environment

Table 2. Position and effect of quantitative trait loci (QTLs) detected for adult plant resistance to leaf rust (LR) and stripe rust (YR) in each environment, using disease severity, area under the disease progress curve, and the mean of final disease severity using 142 recombinant inbred lines derived from Apav\#1 $\times$ Ableu\#1

\begin{tabular}{|c|c|c|c|c|c|c|c|}
\hline QTL & Traits & Position (cM) & Marker interval & Physical position (Mb) & LOD $^{w}$ & $\operatorname{PVE}(\%)^{x}$ & Add $^{y}$ \\
\hline QLr.cim-1BL.1 & LR2016 & 82 & $\begin{array}{l}\text { 5411162|F|0-35:A }>\mathrm{C}-35: \mathrm{A}>\mathrm{C}-1132278 \mid \\
\mathrm{F} \mid 0-20: \mathrm{C}>\mathrm{T}-20: \mathrm{C}>\mathrm{T}\end{array}$ & $669.2-673.7$ & 37.1 & 51.1 & 15.3 \\
\hline \multirow[t]{5}{*}{$(\operatorname{Lr} 46)$} & LR2016AU & 81 & $\begin{array}{l}\text { 5411162|F|0-35:A }>\mathrm{C}-35: \mathrm{A}>\mathrm{C}-1132278 \mid \\
\mathrm{F} \mid 0-20: \mathrm{C}>\mathrm{T}-20: \mathrm{C}>\mathrm{T}\end{array}$ & $669.2-673.7$ & 28.1 & 33.2 & 152.6 \\
\hline & LR2017 & 81 & $\begin{array}{l}\text { 5411162|F|0-35:A }>\mathrm{C}-35: \mathrm{A}>\mathrm{C}-1132278 \mid \\
\mathrm{F} \mid 0-20: \mathrm{C}>\mathrm{T}-20: \mathrm{C}>\mathrm{T}\end{array}$ & $669.2-673.7$ & 33.3 & 45.4 & 18.8 \\
\hline & LR2018 & 81 & $\begin{array}{l}\text { 5411162|F|0-35:A }>\mathrm{C}-35: \mathrm{A}>\mathrm{C}-1132278 \mid \\
\mathrm{F} \mid 0-20: \mathrm{C}>\mathrm{T}-20: \mathrm{C}>\mathrm{T}\end{array}$ & $669.2-673.7$ & 34.6 & 51.6 & 20.9 \\
\hline & LR2018AU & 82 & $\begin{array}{l}\text { 5411162|F|0-35:A }>\mathrm{C}-35: \mathrm{A}>\mathrm{C}-1132278 \mid \\
\mathrm{F} \mid 0-20: \mathrm{C}>\mathrm{T}-20: \mathrm{C}>\mathrm{T}\end{array}$ & $669.2-673.7$ & 36.0 & 15.8 & 115.9 \\
\hline & LRM & 82 & $\begin{array}{l}\text { 5411162|F|0-35:A }>\mathrm{C}-35: \mathrm{A}>\mathrm{C}-1132278 \mid \\
\mathrm{F} \mid 0-20: \mathrm{C}>\mathrm{T}-20: \mathrm{C}>\mathrm{T}\end{array}$ & $669.2-673.7$ & 37.9 & 29.0 & 20.4 \\
\hline \multirow[t]{5}{*}{ QLr.cim-1BL.2 } & LRM & 104 & $\begin{array}{l}\text { 100041322|F|0-38:A>G-38:A>G- }- \\
\text { 100084210|F|0-16:A>G-16:A>G }\end{array}$ & $675.4-680.2$ & 13.6 & 7.0 & 10.1 \\
\hline & LR2016AU & 118 & $2303890^{z} \_2253824|\mathrm{~F}| 0-43: \mathrm{G}>\mathrm{A}-43: \mathrm{G}>\mathrm{A}$ & 680.1 & 9.0 & 7.5 & 72.3 \\
\hline & LR2017 & 119 & 2269974|F|0-24:G>A-24:G>A $\mathrm{A}^{\mathrm{z}}-1716123^{\mathrm{z}}$ & - & 38.4 & 29.0 & 22.8 \\
\hline & LR2018 & 119 & 2269974|F|0-24:G>A-24:G>A $-1716123^{z}$ & - & 18.3 & 17.7 & 9.7 \\
\hline & LR2018AU & 119 & 2269974|F|0-24:G>A-24:G>A $-1716123^{z}$ & - & 49.3 & 28.6 & 155.6 \\
\hline \multirow[t]{4}{*}{ QLr.cim-3DS } & LR2017 & 105 & $1233406-3941237$ & $136.4-136.4$ & 5.4 & 2.2 & 6.4 \\
\hline & LR2018 & 105 & $1233406-3941237$ & $136.4-136.4$ & 4.7 & 4.0 & 5.9 \\
\hline & LR2018AU & 105 & $1233406-3941237$ & $136.4-136.4$ & 7.0 & 1.8 & 39.8 \\
\hline & LRM & 105 & $1233406-3941237$ & $136.4-136.4$ & 4.6 & 1.9 & 5.3 \\
\hline \multirow[t]{5}{*}{ QLr.cim-7BL } & LR2016 & 416 & $1089497^{z}-1121184$ & 745.0 & 11.5 & 16.1 & 5.5 \\
\hline & LR2017 & 417 & $1121184-1033503|\mathrm{~F}| 0-6: \mathrm{A}>\mathrm{G}-6: \mathrm{A}>\mathrm{G}^{\mathrm{Z}}$ & 745.0 & 17.5 & 31.3 & 11.9 \\
\hline & LR2018 & 418 & $1121184-1033503|\mathrm{~F}| 0-6: \mathrm{A}>\mathrm{G}-6: \mathrm{A}>\mathrm{G}^{\mathrm{z}}$ & 745.0 & 15.4 & 13.7 & 8.6 \\
\hline & LR2018AU & 417 & $1121184-1033503|\mathrm{~F}| 0-6: \mathrm{A}>\mathrm{G}-6: \mathrm{A}>\mathrm{G}^{\mathrm{z}}$ & 745.0 & 21.4 & 7.2 & 78.6 \\
\hline & LRM & 417 & $1121184-1033503|\mathrm{~F}| 0-6: \mathrm{A}>\mathrm{G}-6: \mathrm{A}>\mathrm{G}^{\mathrm{z}}$ & 745.0 & 30.6 & 20.5 & 17.2 \\
\hline QYr.cim-1BL.1 & YR2015 & 81 & $\begin{array}{l}\text { 5411162|F|0-35:A }>C-35: A>C-1132278 \mid \\
\text { F|0-20:C }>\mathrm{T}-20: C>T\end{array}$ & $669.2-673.7$ & 17.2 & 25.8 & 12.1 \\
\hline \multirow[t]{5}{*}{$(Y r 29)$} & YR2015AU & 82 & $\begin{array}{l}\text { 5411162|F|0-35:A }>\mathrm{C}-35: \mathrm{A}>\mathrm{C}-1132278 \mid \\
\mathrm{F} \mid 0-20: \mathrm{C}>\mathrm{T}-20: \mathrm{C}>\mathrm{T}\end{array}$ & $669.2-673.7$ & 18.1 & 20.3 & 67.4 \\
\hline & YR2016 & 81 & $\begin{array}{l}\text { 5411162|F|0-35:A }>\mathrm{C}-35: \mathrm{A}>\mathrm{C}-1132278 \mid \\
\mathrm{F} \mid 0-20: \mathrm{C}>\mathrm{T}-20: \mathrm{C}>\mathrm{T}\end{array}$ & $669.2-673.7$ & 29.3 & 31.7 & 15.9 \\
\hline & YR2016AU & 81 & $\begin{array}{l}\text { 5411162|F|0-35:A }>\mathrm{C}-35: \mathrm{A}>\mathrm{C}-1132278 \mid \\
\mathrm{F} \mid 0-20: \mathrm{C}>\mathrm{T}-20: \mathrm{C}>\mathrm{T}\end{array}$ & $669.2-673.7$ & 24.4 & 40.8 & 187.1 \\
\hline & YRK2016 & 81 & $\begin{array}{l}\text { 5411162|F|0-35:A }>\mathrm{C}-35: \mathrm{A}>\mathrm{C}-1132278 \mid \\
\mathrm{F} \mid 0-20: \mathrm{C}>\mathrm{T}-20: \mathrm{C}>\mathrm{T}\end{array}$ & $669.2-673.7$ & 9.1 & 29.4 & 8.2 \\
\hline & YRM & 81 & $\begin{array}{l}\text { 5411162|F|0-35:A }>\mathrm{C}-35: \mathrm{A}>\mathrm{C}-1132278 \mid \\
\mathrm{F} \mid 0-20: \mathrm{C}>\mathrm{T}-20: \mathrm{C}>\mathrm{T}\end{array}$ & $669.2-673.7$ & 28.4 & 47.0 & 14.4 \\
\hline \multirow[t]{6}{*}{ QYr.cim-IBL.2 } & YR2015AU & 104 & $\begin{array}{l}\text { 100041322|F|0-38:A>G-38:A>G- } \\
\text { 100084210|F|0-16:A>G-16:A>G }\end{array}$ & $675.4-680.2$ & 13.4 & 14.3 & 57.0 \\
\hline & YRK2016 & 111 & 2275932|F|0-39:A >T-39:A >T-1159592z & 679.3 & 37.1 & 30.6 & 7.0 \\
\hline & YRK16AU & 111 & 2275932|F|0-39:A>T-39:A>T—1159592z & 679.3 & 25.2 & 39.0 & 143.7 \\
\hline & YR2015 & 120 & $2269974|\mathrm{~F}| 0-24: \mathrm{G}>\mathrm{A}-24: \mathrm{G}>\mathrm{A}^{\mathrm{z}}-1716123^{\mathrm{z}}$ & - & 11.8 & 16.1 & 9.6 \\
\hline & YR2016 & 120 & $2269974|\mathrm{~F}| 0-24: \mathrm{G}>\mathrm{A}-24: \mathrm{G}>\mathrm{A}^{\mathrm{z}}-1716123^{\mathrm{z}}$ & - & 24.0 & 23.5 & 13.6 \\
\hline & YRM & 120 & $2269974|\mathrm{~F}| 0-24: \mathrm{G}>\mathrm{A}-24: \mathrm{G}>\mathrm{A}^{\mathrm{z}}-1716123^{\mathrm{z}}$ & - & 8.5 & 10.4 & 6.8 \\
\hline \multirow[t]{2}{*}{ QYr.cim- $2 A L$} & YR2015 & 195 & $1117352 \_4989805$ & $719.5-728.8$ & 3.4 & 4.2 & -4.9 \\
\hline & YR2016 & 194 & 1275924|F|0-18:C>T-18:C>T—1117352 & $719.5-719.5$ & 3.5 & 4.2 & -5.3 \\
\hline \multirow[t]{4}{*}{ QYr.cim- $4 B L$} & YR2015 & 20 & $\begin{array}{l}\text { 1235862|F|0-42:C }>\mathrm{T}-42: \mathrm{C}>\mathrm{T}-1220607|\mathrm{~F}| \\
0-68: \mathrm{T}>\mathrm{C}-68: \mathrm{T}>\mathrm{C}\end{array}$ & $657.9-663.8$ & 2.7 & 7.1 & 7.5 \\
\hline & YR2016 & 22 & $\begin{array}{l}\text { 1235862|F|0-42:C }>\mathrm{T}-42: \mathrm{C}>\mathrm{T}-1220607|\mathrm{~F}| \\
0-68: \mathrm{T}>\mathrm{C}-68: \mathrm{T}>\mathrm{C}\end{array}$ & $657.9-663.8$ & 4.8 & 10.6 & 8.9 \\
\hline & YRK2016AU & 22 & $\begin{array}{l}\text { 1235862|F|0-42:C }>\mathrm{T}-42: \mathrm{C}>\mathrm{T}-1220607|\mathrm{~F}| \\
0-68: \mathrm{T}>\mathrm{C}-68: \mathrm{T}>\mathrm{C}\end{array}$ & $657.9-663.8$ & 3.1 & 9.2 & 76.5 \\
\hline & YRM & 20 & $\begin{array}{l}\text { 1235862|F|0-42:C }>\mathrm{T}-42: \mathrm{C}>\mathrm{T}-1220607|\mathrm{~F}| \\
0-68: \mathrm{T}>\mathrm{C}-68: \mathrm{T}>\mathrm{C}\end{array}$ & $657.9-663.8$ & 2.7 & 7.2 & 7.0 \\
\hline \multirow[t]{3}{*}{ QYr.cim-5AL } & YR2015 & 92 & 1084162|F|0-42:C $>\mathrm{A}-42: \mathrm{C}>\mathrm{A}-1131694^{\mathrm{z}}$ & 572.0 & 19.9 & 10.9 & 7.4 \\
\hline & YR2015AU & 93 & $1131694^{z} \_4911066|F| 0-22: A>G-22: A>G$ & 580.2 & 3.8 & 3.5 & 28.7 \\
\hline & YRK2016 & 92 & 1084162|F|0-42:C>A-42:C>A-1131694z & 572.0 & 4.7 & 2.1 & 1.9 \\
\hline \multirow[t]{3}{*}{ QYr.cim-7DS } & YR2016 & 68 & $1117156-987784|\mathrm{~F}| 0-55: \mathrm{T}>\mathrm{G}-55: \mathrm{T}>\mathrm{G}$ & 199.4-392.8 & 2.9 & 4.1 & -5.3 \\
\hline & YR2016AU & 68 & $1117156-987784|\mathrm{~F}| 0-55: \mathrm{T}>\mathrm{G}-55: \mathrm{T}>\mathrm{G}$ & $199.4-392.8$ & 3.8 & 5.5 & -68.4 \\
\hline & YRM & 67 & $1117156-987784|\mathrm{~F}| 0-55: \mathrm{T}>\mathrm{G}-55: \mathrm{T}>\mathrm{G}$ & 199.4-392.8 & 3.2 & 4.3 & -4.4 \\
\hline
\end{tabular}

\footnotetext{
${ }^{\mathrm{w}}$ Logarithm of odds (LOD) score of QTL peak.

$x$ Proportion of phenotypic variance explained (PVE) by the QTL.

y Additive effect for each QTL.

${ }^{\mathrm{z}}$ Flanking markers that did not find the related physical position on Chinese Spring (RefSeq version 1.1).
} 
in China (Zhang et al. 2017). Thus, the effect of $L r 46 / Y r 29$ varied based on genetic background and rust environment. In the present study, the closely linked cleaved amplified polymorphic sequence marker csLV46G22 for $L r 46 / Y r 29$ was $5.6 \mathrm{cM}(0.9 \mathrm{Mb})$ away from 1132278|F|0-20:C>T-20:C>T, which was closely linked to QLr.cim1BL.1/QYr.cim-1BL.1 (data not shown). Based on the genotype of $c s L V 46 G 22$, we removed the effect of its phenotype in this population and redid the QTL mapping. The results showed that QLr.cim-1BL.1/ QYr.cim-1BL.1 was no longer detectable, but QLr.cim-1BL.2/QYr. cim-1BL.2 remained stable. Therefore, QLr.cim-1BL.1/QYr.cim$1 B L .1$ should be $L r 46 / Y r 29$ and different from $Q L r . c i m-1 B L .2 / Q Y r$. cim-1BL.2.

The International Wheat Genome Sequencing Consortium (2014, 2018) constructed the physical map of the Chinese Spring reference genome, which is contributing to wheat genetics, comparative genomics, and evolution (Shi and Ling 2018). In our study, the physical map of Chinese Spring provided an important reference for the identification and comparison of resistance loci QLr.cim-1BL.1/QYr. cim-1BL.1 and QLr.cim-1BL.2/QYr.cim-1BL.2. Lr46/Yr29 has been detected in many different mapping populations and was found to play a determinant role in our population in conferring APR to LR and YR. Therefore, we compared the physical map of $L r 46 / Y r 29$ with the resistance loci reported in previous studies (Lan et al. 2014; MateosHernandez et al. 2006; Ponce-Molina et al. 2018; Rosewarne et al. 2012; Suenaga et al. 2003; William et al. 2006) to determine its physical position (Fig. 3). Based on the comparative mapping, we identified a common sequence region located between 672.6 and $673.8 \mathrm{Mb}$ map positions, with a high likelihood that $L r 46 / Y r 29$ exists in this chromosomal region. In addition, it is also likely that QLr.cim-1BL.2 and QYr.cim-1BL.2 are the same locus as the QTL detected from Oligoculm and Pavon76 wheat lines (Suenaga et al. 2003; William et al. 2006). This QTL was located in the 678.7 to $680.2 \mathrm{Mb}$ interval.
The map positions of Lr46/Yr29 and QLr.cim-1BL.2/QYr.cim-1BL.2 need further research to clarify.

QLr.cim-3DS was mapped on the short arm of wheat chromosome 3D, based on a high-density GBS map constructed by Li et al. (2015). Thus, only one LR resistance gene, $L r 32$, has been mapped on chromosome 3DS. Thomas et al. (2010) backcrossed Lr32 into the susceptible cultivar Thatcher and its FDS varied from $80 \mathrm{~S}$ to $25 \mathrm{MR}$ on average during 2003 to 2009. Two SSR markers, Xwmc43 and Xbarc 135, were $0.6 \mathrm{cM}$ away from Lr32, but the physical distance between these two markers and the flanking markers of QLr.cim$3 D S$ was around $105.9 \mathrm{Mb}$. In addition, Lr32 is an ASR gene, so QLr.cim-3DS should be different from Lr32. Basnet et al. (2013) detected QLr.tam-3DS in the CIMMYT wheat line Quaiu\#3; it was associated with 3 to $6 \%$ of the variation in LR resistance and 3.2 to $4.3 \%$ in YR resistance. We did not detect any effect on YR from QLr.cim-3DS in our population. Lan et al. (2014) identified QLr.cim-3DC near the centromeric region of chromosome $3 \mathrm{D}$ in the CIMMYT bread wheat line Francolin\#1, but this QTL was $>100 \mathrm{cM}$ away from the locus identified in the present study. Further research is needed to determine whether QLr.cim-3DS is a new LR resistance QTL from Ableu\#1.

QLr.cim-7BL was located on the long arm of chromosome 7B, according to the GBS map constructed by Li et al. (2015). The resistance allele at QLr.cim-7BL was derived from Ableu\#1, and it provided the second largest resistance effect in this population. At present, five LR resistance genes are known to be located on chromosome 7BL: Lr14a (Herrera-Foessel et al. 2008; Law and Johnson 1967), Lr14b (Dyck and Samborski 1970), Lr68 (Herrera-Foessel et al. 2012), LrBil6 (Zhang et al. 2011), and LrFun (Xing et al. 2014). Lr14a, Lr14b, LrBil6, and LrFun are ASR genes that were different from $Q L$ r.cim-7BL. Lr68 is an APR gene closely linked to the codominant marker $c s 7 B L N L R R$ with a genetic distance of

Table 3. Mean leaf rust (LR) severity of lines containing combinations of the indicated quantitative trait loci (QTLs) from the Apav\#1 $\times$ Ableu\#1 recombinant inbred line (RIL) population, highlighting the additive effects of the QTLs

\begin{tabular}{|c|c|c|c|c|c|}
\hline \multirow[b]{2}{*}{ Genotypic class } & \multirow[b]{2}{*}{ RILs (n) } & \multicolumn{4}{|c|}{ Mean LR severity (\%) } \\
\hline & & LR2016 FDS & LR2017 FDS & LR2018 FDS & LR MFDS $^{\mathbf{y}}$ \\
\hline None & 16 & $81.4 \mathrm{~A}^{\mathrm{z}}$ & $95.0 \mathrm{~A}$ & $100.0 \mathrm{~A}$ & $92.4 \mathrm{~A}$ \\
\hline $3 \mathrm{DS}$ & 7 & $81.4 \mathrm{~A}$ & $98.6 \mathrm{~A}$ & $98.6 \mathrm{~A}$ & $92.9 \mathrm{~A}$ \\
\hline 1BL.2 & 2 & $65.0 \mathrm{~A}$ & $70.0 \mathrm{~B}$ & $75.0 \mathrm{C}$ & $70.0 \mathrm{~B}$ \\
\hline $7 \mathrm{BL}$ & 18 & $43.9 \mathrm{~B}$ & $91.7 \mathrm{~A}$ & $93.9 \mathrm{~A}$ & $76.5 \mathrm{~B}$ \\
\hline $3 \mathrm{DS}+7 \mathrm{BL}$ & 5 & $36.0 \mathrm{~B}$ & $68.0 \mathrm{~B}$ & $80.0 \mathrm{~B}$ & $61.3 \mathrm{C}$ \\
\hline Lr46 & 2 & $25.0 \mathrm{C}$ & $40.0 \mathrm{C}$ & $60.0 \mathrm{D}$ & $41.7 \mathrm{D}$ \\
\hline Lr46+1BL.2 & 17 & $13.6 \mathrm{D}$ & $29.4 \mathrm{C}$ & $45.3 \mathrm{E}$ & $29.4 \mathrm{D}$ \\
\hline Lr46+1BL.2+3DS & 17 & $10.8 \mathrm{D}$ & $21.5 \mathrm{D}$ & $29.4 \mathrm{~F}$ & $20.6 \mathrm{E}$ \\
\hline Lr46+1BL.2+7BL & 10 & $2.8 \mathrm{E}$ & $13.6 \mathrm{D}$ & $17.1 \mathrm{G}$ & $11.2 \mathrm{~F}$ \\
\hline$L r 46+1 B L .2+3 \mathrm{DS}+7 \mathrm{BL}$ & 11 & $1.1 \mathrm{E}$ & $2.1 \mathrm{E}$ & $1.7 \mathrm{H}$ & $1.6 \mathrm{G}$ \\
\hline
\end{tabular}

${ }^{\mathrm{x}}$ Final disease severity (FDS)

${ }^{y}$ Mean of final disease severity (MFDS).

${ }^{\mathrm{z}}$ Different letters following the mean indicate significant differences based on a $t$ test $(P<0.01)$.

Table 4. Mean stripe rust (YR) severity on lines containing combinations of the indicated quantitative trait loci (QTLs) from the Apav\#1 $\times$ Ableu\#1 recombinant inbred line (RIL) population, highlighting the additive effects of the QTLs

\begin{tabular}{|c|c|c|c|c|c|}
\hline \multirow[b]{2}{*}{ Genotypic class } & \multirow[b]{2}{*}{ RILs (n) } & \multicolumn{4}{|c|}{ Mean YR severity (\%) } \\
\hline & & YR2015 FDS $^{x}$ & YR2016 FDS & YRK2016 FDS & YR MFDS $^{y}$ \\
\hline None & 9 & $81.1 \mathrm{~A}^{\mathrm{z}}$ & $92.2 \mathrm{~A}$ & $55.6 \mathrm{~A}$ & $76.3 \mathrm{~A}$ \\
\hline $5 \mathrm{AL}$ & 10 & $71.0 \mathrm{~A}$ & $80.0 \mathrm{~A}$ & $55.0 \mathrm{~A}$ & $68.3 \mathrm{~A}$ \\
\hline $4 \mathrm{BL}$ & 9 & $57.8 \mathrm{~B}$ & $79.0 \mathrm{~A}$ & $55.6 \mathrm{~A}$ & $64.4 \mathrm{~A}$ \\
\hline $4 \mathrm{BL}+5 \mathrm{AL}$ & 12 & $50.8 \mathrm{C}$ & $60.0 \mathrm{~B}$ & $42.5 \mathrm{~B}$ & $51.1 \mathrm{~B}$ \\
\hline Yr29+1BL.2+5AL & 15 & $23.0 \mathrm{D}$ & $24.3 \mathrm{C}$ & $23.7 \mathrm{C}$ & $23.7 \mathrm{C}$ \\
\hline$Y r 29+1 B L .2+4 B L$ & 8 & $16.9 \mathrm{D}$ & $14.4 \mathrm{C}$ & $15.6 \mathrm{C}$ & $15.6 \mathrm{C}$ \\
\hline $\operatorname{Yr} 29+1$ BL. 2 & 5 & $16.0 \mathrm{D}$ & $25.0 \mathrm{C}$ & $27.0 \mathrm{C}$ & $22.7 \mathrm{C}$ \\
\hline$Y r 29+1 B L .2+4 B L+5 A L$ & 16 & $13.3 \mathrm{D}$ & $15.0 \mathrm{C}$ & $15.6 \mathrm{C}$ & $14.6 \mathrm{C}$ \\
\hline
\end{tabular}

${ }^{x}$ Final disease severity (FDS).

${ }^{\mathrm{y}}$ Mean of final disease severity (MFDS).

${ }^{\mathrm{z}}$ Different letters following the mean indicate significant differences based on a $t$ test $(P<0.01)$. 
$0.8 \mathrm{cM}$. In our study, $c s 7 B L N L R R$ was used to genotype the population and mapped $5.7 \mathrm{cM}(4.8 \mathrm{Mb}$ ) away from QLr.cim-7BL (data not shown). Thus, $Q L$ r.cim-7BL might be $L r 68$, based on its minor effect for rust and its chromosome position.

QYr.cim- $2 A L$ was located on the wheat chromosome $2 \mathrm{AL}$. The resistance allele of this locus was derived from Apav\#1. Only two YR resistance genes, $Y r 1$ and $Y r 32$, have been identified on 2AL. $\mathrm{Yrl}$ was mapped 33 to $35 \mathrm{cM}$ away from $\mathrm{Yr} 32$ (Eriksen et al. 2004), and both are ASR genes (Pathan et al. 2008). In addition, the physical map interval between these two genes and $Q Y r$. cim- $2 A L$ was $>10 \mathrm{Mb}$, based on the Chinese Spring genome sequence, indicating that $Q Y r$.cim- $2 A L$ should be different from $\mathrm{Yrl}$ and $Y r 32$. There could also be a rust-resistance loci cluster on the 2AL chromosome region, and QYr.cim- $2 A L$ might be a new minor YR resistance gene.

QYr.cim-7DS was detected on wheat chromosome 7DS. Thus, the known pleiotropic APR gene $L r 34 / Y r 18$ has been located on chromosome 7DS (Singh 1992; Suenaga et al. 2003). This locus provides moderate levels of durable resistance to both LR and YR when present alone, and it can provide adequate disease resistance in most environments when combined with three or four minor genes in a wheat variety (Singh and Rajaram 1993). Several QTLs, such as QYr.sgi-7D contributed by cultivar Kariega (Ramburan et al. 2004) and QYr.caas-7DS from cultivars Libellula and Strampelli (Lu et al. 2009), were confirmed to be $L r 34 / Y r 18$, and this pleiotropic gene can provide significant rust resistance. However, QYr.cim-7DS mapped $38.4 \mathrm{cM}$ away from $L r 34 / Y r 18$, based on the GBS consensus map provided by Li et al. (2015), and we only detected a minor effect on YR from $Q Y$ r.cim-7DS, so we conclude that QYr.cim-7DS is unlikely to be Yr18. Liu et al. (2015) also mapped a YR resistance locus on this chromosome, QYr.caas-7DS, from a susceptible parent Linmai 2 , and it explained $9.1 \%$ of the phenotypic variation for resistance in a rust-prone environment in China. QYr.cim-7DS should be different from QYr.caas-7DS, given the physical distance of $>100 \mathrm{Mb}$ between them, in accordance with the Chinese Spring genome sequence. $Q Y r$. cim-7DS might thus constitute a new minor YR resistance QTL.

Currently, only two YR APR genes have been reported on the 4BL region: Yr50 and Yr62. Liu et al. (2013) detected Yr50 from a

\begin{tabular}{|c|c|c|c|c|c|c|}
\hline $\begin{array}{l}\text { @ } \\
\omega \\
\precsim\end{array}$ & 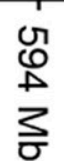 & $\begin{array}{l}\text { ज़ } \\
\text { c } \\
3\end{array}$ & $\begin{array}{l}\omega \\
\text { య } \\
\text { क } \\
\text { उ }\end{array}$ & $\begin{array}{l}\underset{\mho}{0} \\
\underset{\sigma}{3}\end{array}$ & $\begin{array}{l}\vec{\emptyset} \\
\infty \\
\precsim\end{array}$ & $\begin{array}{l}\mathscr{6} \\
3 \\
3\end{array}$ \\
\hline
\end{tabular}

1. Suenaga et al. (2003)

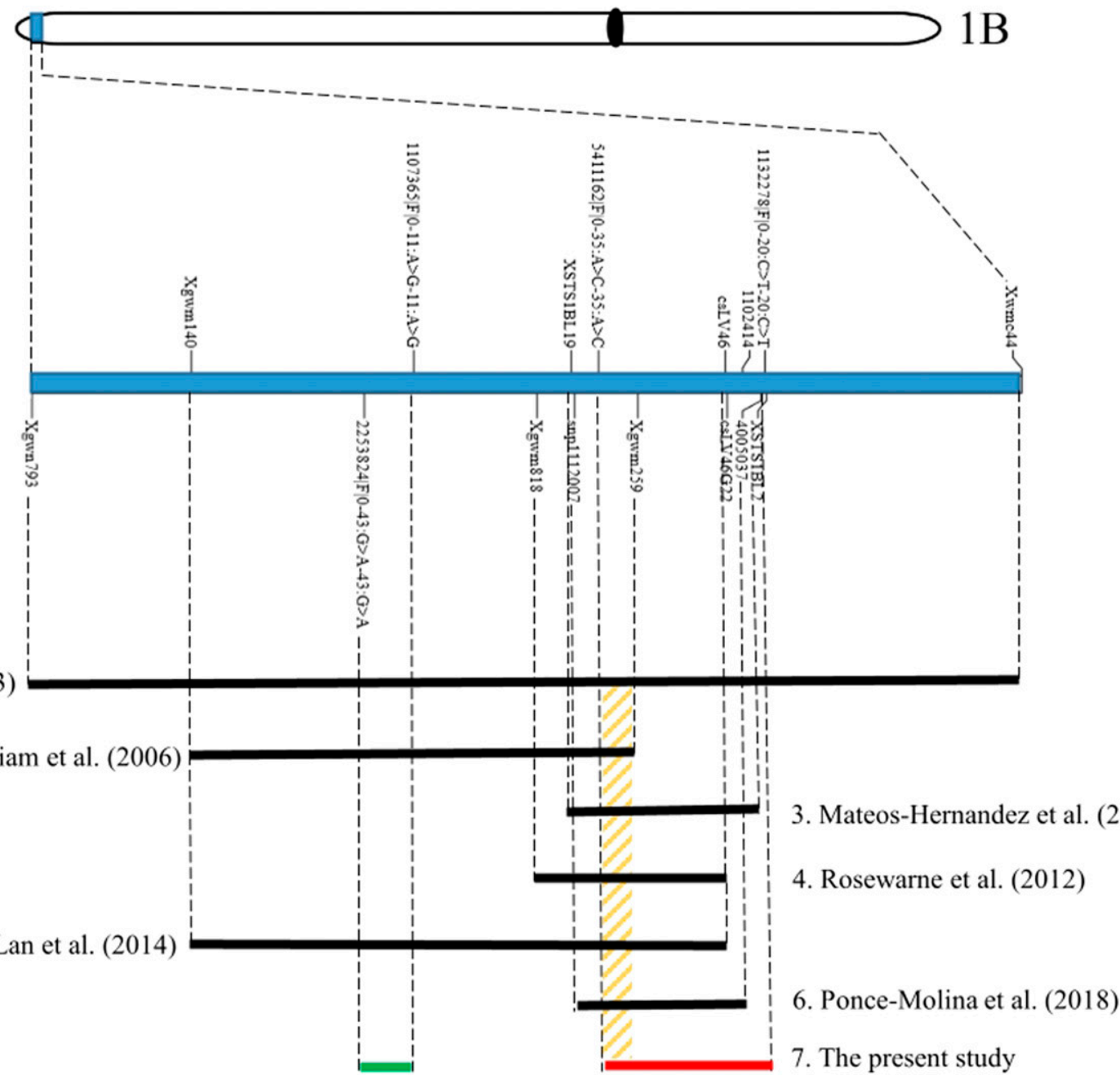

Fig. 3. Physical locations of $L r 46 / Y r 29$ based on published results and the present study, using the Chinese Spring genome sequence as a reference. The bold black lines (numbers 1 to 6) indicate the detected physical locations for Lr46/Yr29, as per Suenaga et al. (2003), William et al. (2006), Mateos-Hernandez et al. (2006), Rosewarne et al. (2012), Lan et al. (2014), and Ponce-Molina et al. (2018), respectively. The bold red line (number 7) represents the physical location of QLr.cim-1BL.1/QYr.cim-1BL.1 (Lr46/Yr29) in our study. The shaded yellow slash indicates the colocated area in all seven studies mentioned above, and the bold green line (number 7) represents the physical location for QLr.cim-1BL.2I QYr.cim-1BL.2 detected in the present study. 
homogeneous $\mathrm{BC}_{2} \mathrm{~F}_{6}$-derived resistant wheat line $\mathrm{CH} 223$ and SSR markers Xbarc1096 and Xwmc47, with 8.0 and $7.2 \mathrm{cM}$, respectively. The infection type score of $Y r 50$ ranged between 0 and 2 based on a 0 to 9 scale. The interval between Xwmc47 and flanking markers of QYr.cim- $4 B L$ was $>12 \mathrm{Mb}$. Thus, $Q Y$ r.cim- $4 B L$ should be different from $\operatorname{Yr} 50$, based on the locations of the chromosome and the types of infection. Yr62 is a high-temperature APR gene derived from wheat landrace PI 192252 and accounted for 40 to $60 \%$ of the phenotypic variation in relative AUDPC (Lu et al. 2014). It was flanked by SSR markers Xgwm251 and Xgwm192 at $88 \mathrm{Mb}$ from QYr.cim-4BL, based on the chromosome positions of flanking molecular markers. Thus, QYr.cim-4BL cannot be Yr62. In addition, several YR QTLs were also mapped on this chromosome; for instance, QYr.caas-4BL was found in cultivars Libellula and Strampelli, accounting for $4.5 \%$ and for 3.1 to $5.1 \%$, respectively of the phenotypic variances for YR resistance in their corresponding populations (Lu et al. 2009). QYr.caas-4BL was flanked by SSR markers $X g w m 165$ and $X g w m 149$, with a physical distance of $108 \mathrm{Mb}$ from QYr.cim-4BL. QYr.nwafu-4BL was detected in the resistant line P10103, which accounted for 42 to $55 \%$ of the phenotypic variances of DS (Wu et al. 2018). This locus was flanked by SNP markers $A X-110963704$ and $A X-110519862$, and the physical distance was $12.3 \mathrm{Mb}$ between $Q Y$ r.nwafu- $4 B L$ and $Q Y$ r.cim- $4 B L$, based on the Chinese Spring genome reference map. Detailed allelism tests are needed to further verify the relationship between $Q Y$ r.cim- $4 B L$ and the reported QTLs.

QYr.cim-5AL was located on the long arm of chromosome 5A, and the resistance allele at this locus was derived from the resistant parent Ableu\#1. Thus, only two known YR resistance genes, $\operatorname{Yr} 34$ and $Y r 48$, are mapped on the 5AL region. $Y r 34$, an ASR gene, is flanked by an SSR marker Xgwm410.2 (Bariana et al. 2006), whereas $Y r 48$ is located in the distal region of chromosome $5 \mathrm{AL}$ and flanked by Xwmc727 and Xcfa2149 (Lowe et al. 2011). QYr.cim-5AL is neither Yr34 nor $Y r 48$, given the large physical map intervals between Xgwm410.2 and QYr.cim-5AL, and Xwmc727 and QYr.cim-5AL (80.5 Mb and 107.9 Mb, respectively, based on the Chinese Spring genome sequence). Wu et al. (2018) detected a YR resistance QTL, QYrpas.cim-5AL, from wheat line P10103 and it explained $15.3 \%$ of the phenotypic variation for infection type and $12.0 \%$ of the phenotypic variation for DS. QYrpas.cim-5AL might be identical to the QTL reported by Rosewarne et al. (2012) in the CIMMYT wheat line Pastor, based on the chromosome position of flanking markers. The QTL from P10103 and Pastor was located on the distal region of the $5 \mathrm{AL}$ wheat chromosome with a genetic distance of $>90 \mathrm{Mb}$ from QYr.cim-5AL. Thus, QYr.cim-5AL might be a new YR resistance locus.

The high level of APR to leaf rust and stripe rust in Ableu\#1 is likely to remain durable owing to the involvement of multiple additive effect APR genes including Lr46/Yr29/Sr58. Ableu\#1 also carries a good level of APR to races of the SR fungus ( $P$. graminis f. sp. tritici) prevalent in East Africa and it likely carries the durable APR gene $S r 2$ (results not shown). The detection of a second pleiotropic resistance allele, QLr.cim-1BL.2/QYr.cim-1BL.2, linked to $L r 46 / Y r 29 / S r 58$ makes Ableu\#1 an important parent for utilization in breeding to achieve APR to all three rusts. Although the flanking molecular markers identified in our study can aid the selection of APR alleles, further studies are required to develop closely linked markers and to characterize QLr.cim$1 B L .2 / Q Y$ r.cim-1BL.2. We were unable to construct the linkage maps for chromosomes 4D and 5D owing to low marker density. Developing more molecular markers for these chromosomes will be critical for future research when using the DArT-GBS genotyping platform.

\section{Acknowledgments}

We appreciate the editing by Mike Listman.

\section{Literature Cited}

Ahmed, S., Bux, H., Rasheed, A., Kazi, A. G., Rauf, A., Mahmood, T., and MujeebKazi, A. 2014. Stripe rust resistance in Triticum durum-T. monococcum and T. durum-T. urartu amphiploids. Aus. Plant Pathol. 43:109-113.
Baird, N. A., Etter, P. D., Atwood, T. S., Currey, M. C., Shiver, A. L., Lewis, Z. A., Selker, E. U., Cresko, W. A., and Johnson, E. A. 2008. Rapid SNP discovery and genetic mapping using sequenced RAD markers. PLoS One 3:e3376.

Bariana, H. S., Parry, N., Barclay, I. R., Loughman, R., Mclean, R. J., Shankar, M. Wilson, R. E., Willey, N. J., and Francki, M. 2006. Identification and characterization of stripe rust resistance gene $\operatorname{Yr} 34$ in common wheat. Theor. Appl. Genet. 112:1143-1148.

Basnet, B. R., Singh, R. P., Ibrahim, A. M. H., Herrera-Foessel, S. A., HuertaEspino, J., Lan, C. X., and Rudd, J. C. 2013. Characterization of Yr54 and other genes associated with adult plant resistance to yellow rust and leaf rust in common wheat Quaiu 3. Mol. Breed. 33:385-399.

Beddow, J. M., Pardey, P. G., Yuan, C., Hurley, T. M., Kriticos, D. J., Braun, H. J., Park, R. F., Cuddy, W. S., and Yonow, T. 2015. Research investment implications of shifts in the global geography of wheat stripe rust. Nat. Plants 1:15132.

Bjarko, M. E., and Line, R. F. 1988. Heritability and number of genes controlling leaf rust resistance in four cultivars of wheat. Phytopathology 78:457-461.

Bolton, M. D., Kolmer, J. A., and Garvin, D. F. 2008. Wheat leaf rust caused by Puccinia triticina. Mol. Plant Pathol. 9:563-575.

Chen, X. M. 2005. Epidemiology and control of stripe rust [Puccinia striiformis $\mathrm{f}$. sp. tritici] on wheat. Can. J. Plant Pathol. 27:314-337.

Draz, I. S., Abou-Elseoud, M. S., Kamara, A. E. M., Alaa-Eldein, O. A. E., and El-Bebany, A. F. 2015. Screening of wheat genotypes for leaf rust resistance along with grain yield. J. Agric. Sci. 60:29-39.

Dreisigacker, S., Sehgal, D., Luna, G. B., Reyes, A. E., and Mollins, J. 2016. CIMMYT Wheat Molecular Genetics Laboratory Protocols and Applications to Wheat Breeding. CIMMYT, Mexico D.F., Mexico.

Dubin, H. J., and Brennan, J. P. 2009. Fighting a 'shifty enemy'. Pages 19-24 in: The International Collaboration to Contain Wheat Rusts. International Food Policy Research Institute, Washington, DC.

Dyck, P. L., Kerber, E. R., and Lukow, O. M. 1987. Chromosome location and linkage of a new gene (Lr33) for reaction to Puccinia recondita in common wheat. Genome 29:463-466.

Dyck, P. L., and Samborski, D. J. 1970. The genetics of two alleles for leaf rust resistance at the Lr14 locus in wheat. Can. J. Genet. Cytol. 12:689-694.

Dyck, P. L., and Sykes, E. E. 1994. Genetics of leaf-rust resistance in three spelt wheats. Can. J. Plant Sci. 74:231-233.

Elbasyoni, I. S., Lorenz, A. J., Guttieri, M., Frels, K., Baenziger, P. S., Poland, J., and Akhunov, E. 2018. A comparison between genotyping-by-sequencing and array-based scoring of SNPs for genomic prediction accuracy in winter wheat. Plant Sci. 270:123-130.

Elshire, R. J., Glaubitz, J. C., Sun, Q., Poland, J. A., Kawamoto, K., Buckler, E. S., and Mitchell, S. E. 2011. A robust, simple genotyping-by-sequencing (GBS) approach for high diversity species. PLoS One 6:e19379.

Eriksen, L., Afshari, F., Christiansen, M. J., McIntosh, R. A., Jahoor, A., and Wellings, C. R. 2004. Yr32 for resistance to stripe (yellow) rust present in the wheat cultivar Carstens V [published erratum appears in Theor. Appl. Genet. 2004;108:576]. Theor. Appl. Genet. 108:567-575.

Feng, J. Y., Wang, M. N., Deven, R. S., Chao, S. M., Zheng, Y. L., and Chen, X. M. 2018. Characterization of novel gene $\operatorname{Yr} 79$ and four additional quantitative trait loci for all-stage and high-temperature adult-plant resistance to stripe rust in spring wheat PI 182103. Phytopathology 108:737-747.

Helguera, M., Vanzetti, L., Soria, M., Khan, I. A., Kolmer, J., and Dubcovsky, J. 2005. PCR markers for Triticum speltoides leaf rust resistance gene Lr51 and their use to develop isogenic hard red spring wheat lines. Crop Sci. 45:728-734.

Herrera-Foessel, S. A., Singh, R. P., Huerta-Espino, J., Rosewarne, G. M., Periyannan, S. K., Viccars, L., Calvo-Salazar, V., Lan, C. X., and Lagudah, E. S. 2012. Lr68: A new gene conferring slow rusting resistance to leaf rust in wheat. Theor. Appl. Genet. 124:1475-1486.

Herrera-Foessel, S. A., Singh, R. P., Huerta-Espino, J., William, H. M., Garcia, V., Djurle, A., and Yuen, J. 2008. Identification and molecular characterization of leaf rust resistance gene $\mathrm{LrIH} a$ in durum wheat. Plant Dis. 92:469-473.

Huerta-Espino, J., and Singh, R. P. 2017. First detection of virulence in Puccinia striiformis f. sp. tritici to resistance genes $Y r 10$ and $Y r 24(=Y r 26)$ in Mexico. Plant Dis. 101:1676.

International Wheat Genome Sequencing Consortium. 2014. A chromosomebased draft sequence of the hexaploid bread wheat (Triticum aestivum) genome. Science 345:1251788.

International Wheat Genome Sequencing Consortium. 2018. Shifting the limits in wheat research and breeding using a fully annotated reference genome. Science 361:eaar7191.

Joshi, K. D., Ullah, G., Rehman, A. U., Javaid, M. M., Ahmad, J., Hussain, M., Pacheco, A., Khalil, I. A., and Baloch, A. 2017. Wheat yield response to foliar fungicide application against leaf rust caused by Puccinia triticina. J. Agric. Sci. Technol. Iran 7:160-168.

Kolmer, J. A. 1996. Genetics of resistance to wheat leaf rust. Annu. Rev. Phytopathol. 34:435-455.

Kolmer, J. A. 2013. Leaf rust of wheat: Pathogen biology, variation and host resistance. Forests 4:70-84.

Kthiri, D., Loladze, A., MacLachlan, P. R., N'Diaye, A., Walkowiak, S., Nilsen, K., Dreisigacker, S., Ammar, K., and Pozniak, C. J. 2018. Characterization and mapping of leaf rust resistance in four durum wheat cultivars. PLoS One 13:e0197317. 
Lan, C. X., Basnet, B. R., Singh, R. P., Huerta-Espino, J., Herrera-Foessel, S. A., Ren, Y., and Randhawa, M. S. 2017. Genetic analysis and mapping of adult plant resistance loci to leaf rust in durum wheat cultivar Bairds. Theor. Appl. Genet. 130:609-619.

Lan, C. X., Singh, R. P., Huerta-Espino, J., Calvo-Salazar, V., and HerreraFoessel, S. A. 2014. Genetic analysis of resistance to leaf rust and stripe rust in wheat cultivar Francolin\#1. Plant Dis. 98:1227-1234.

Lan, C. X., Zhang, Y. L., Herrera-Foessel, S. A., Basnet, B. R., Huerta-Espino, J., Lagudah, E. S., and Singh, R. P. 2015. Identification and characterization of pleiotropic and co-located resistance loci to leaf rust and stripe rust in bread wheat cultivar Sujata. Theor. Appl. Genet. 128:549-561.

Law, C. N., and Johnson, R. 1967. A genetic study of leaf rust resistance in wheat. Can. J. Genet. Cytol. 9:805-822.

Li, H. H., Vikram, P., Singh, R. P., Kilian, A., Carling, J., Song, J., Burgueno-Ferreira, J. A., Bhavani, S., Huerta-Espino, J., Payne, T., Sehgal, D., Wenzl, P., and Singh, S. 2015. A high density GBS map of bread wheat and its application for dissecting complex disease resistance traits. BMC Genomics 16:216.

Li, Q., Guo, J., Chao, K. X., Yang, J., Yue, W. Y., Ma, D. F., and Wang, B. T. 2018a. High-density mapping of an adult-plant stripe rust resistance gene YrBai in wheat landrace Baidatou using the whole genome DArTseq and SNP analysis. Front. Plant Sci. 9:1120.

Li, W., Song, G. Q., Zhang, R. Z., Li, Y. L., Zhang, S. J., Gao, J., and Li, G. Y. 2018b. Present situations and prospects for several pleiotropic disease resistance genes in wheat. J. Triticeae Crops 38:791-797.

Liu, J., Chang, Z. J., Zhang, X. J., Yang, Z. J., Li, X., Jia, J. Q., Zhan, H. X., Guo, H. J., and Wang, J. M. 2013. Putative Thinopyrum intermedium-derived stripe rust resistance gene $\operatorname{Yr} 50$ maps on wheat chromosome arm 4BL. Theor. Appl. Genet. 126:265-274.

Liu, J. D., He, Z. H., Wu, L., Bai, B., Wen, W. E., Xie, C. J., and Xia, X. C. 2015. Genome-wide linkage mapping of QTL for adult-plant resistance to stripe rust in a Chinese wheat population Linmai $2 \times$ Zhong 892. PLoS One 10:e0145462.

Lowe, I., Jankuloski, L., Chao, S. M., Chen, X. M., See, D., and Dubcovsky, J. 2011. Mapping and validation of QTL which confer partial resistance to broadly virulent post-2000 North American races of stripe rust in hexaploid wheat. Theor. Appl. Genet. 123:143-157.

Lu, Y., Wang, M. N., Chen, X. M., See, D., Chao, S. M., and Jing, J. X. 2014. Mapping of Yr62 and a small-effect QTL for high-temperature adult-plant resistance to stripe rust in spring wheat PI 192252. Theor. Appl. Genet. 127: 1449-1459.

Lu, Y. M., Lan, C. X., Liang, S. S., Zhou, X. C., Liu, D., Zhou, G., Lu, Q. L., Jing, J. X., Wang, M. N., Xia, X. C., and He, Z. H. 2009. QTL mapping for adultplant resistance to stripe rust in Italian common wheat cultivars Libellula and Strampelli. Theor. Appl. Genet. 119:1349-1359.

Mascher, M., Muehlbauer, G. J., Rokhsar, D. S., Chapman, J., Schmutz, J., Barry, K., Muñoz-Amatrían, M., Close, T. J., Wise, R. P., Schulman, A. H., Himmelbach, A., Mayer, K. F. X., Scholz, U., Poland, J. A., Stein, N., and Waugh, R. 2013. Anchoring and ordering NGS contig assemblies by population sequencing (POPSEQ). Plant J. 76:718-727.

Mateos-Hernandez, M., Singh, R. P., Hulbert, S. H., Bowden, R. L., HuertaEspino, J., Gill, B. S., and Brown-Guedira, G. 2006. Targeted mapping of ESTs linked to the adult plant resistance gene Lr46 in wheat using synteny with rice. Funct. Integr. Genomics 6:122-131.

McIntosh, R. A., Dubcovsky, J., Rogers, W. J., Morris, C., Appels, R., and Xia, X. C. 2017. Catalogue of gene symbols for wheat: 2017 supplement. https:// shigen.nig.ac.jp/wheat/komugi/genes/symbolClassList.jsp;jsessionid= 82FB82BE7FE833C40CB82EAB6305D786.4 5

Meng, L., Li, H. H., Zhang, L. Y., and Wang, J. K. 2015. QTL IciMapping: Integrated software for genetic linkage map construction and quantitative trait locus mapping in biparental populations. Crop J. 3:269-283.

Mir, R. R., Bhat, J. A., Jan, N., Singh, B., Razdan, A. K., Bhat, M. A., Kumar, A., Srivastava, E., and Malviya, N. 2014. Role of molecular markers. Pages 165-185 in: Alien Gene Transfer in Crop Plants. A. Pratap and J. Kumar, eds. Springer, New York, NY.

Mohler, V., Singh, D., Singrün, C., and Park, R. F. 2012. Characterization and mapping of Lr65 in spelt wheat 'Altgold Rotkorn'. Plant Breed. 131:252-257.

Pathan, A. K., Wellings, C. R., Bariana, H. S., and Park, R. F. 2008. Evaluation of seedling and adult plant resistance in European wheat cultivars to Australian isolates of Puccinia striiformis f. sp. tritici. Euphytica 163:283-301.

Peterson, R. F., Campbell, A. B., and Hannah, A. E. 1948. A diagrammatic scale for estimating rust intensity on leaves and stems of cereals. Can. J. Res. 26c: 496-500.

Pinto da Silva, G. B., Zanella, C. M., Martinelli, J. A., Chaves, M. S., Hiebert, C. W., McCallum, B. D., and Boyd, L. A. 2018. Quantitative trait loci conferring leaf rust resistance in hexaploid wheat. Phytopathology 108:1344-1354.

Poland, J. A., Brown, P. J., Sorrells, M. E., and Jannink, J. L. 2012a. Development of high-density genetic maps for barley and wheat using a novel two-enzyme genotyping-by-sequencing approach. PLoS One 7:e32253.

Poland, J. A., Endelman, J., Dawson, J., Rutkoski, J., Wu, S. Y., Manes, Y., Dreisigacker, S., Crossa, J., Sánchez-Villeda, H., Sprrells, M., and Jannink, J. L. 2012b. Genomic selection in wheat breeding using genotyping-bysequencing. Plant Genome 5:103-113.

Poland, J. A., and Rife, T. W. 2012. Genotyping-by-sequencing for plant breeding and genetics. Plant Genome 5:92-102.
Ponce-Molina, L. J., Huerta-Espino, J., Singh, R. P., Basnet, B. R., Alvarado, G. Randhawa, M. S., and Lan, C. X. 2018. Characterization of leaf rust and stripe rust resistance in spring wheat 'Chilero'. Plant Dis. 102:421-427.

Ramburan, V. P., Pretorius, Z. A., Louw, J. H., Boyd, L. A., Smith, P. H., Boshoff, W. H. P., and Prins, R. 2004. A genetic analysis of adult plant resistance to stripe rust in the wheat cultivar Kariega. Theor. Appl. Genet. 108:1426-1433.

Rinaldo, A., Gilbert, B., Boni, R., Krattinger, S. G., Singh, D., Park, R. F., Lagudah, E., and Ayliffe, M. 2017. The Lr34 adult plant rust resistance gene provides seedling resistance in durum wheat without senescence. Plant Biotechnol. J. 15:894-905.

Roelfs, A. P., Singh, R. P., and Saari, E. E. 1992. Rust Diseases of Wheat: Concepts and Methods of Disease Management. CIMMYT, Mexico D.F., Mexico.

Rosewarne, G. M., Singh, R. P., Huerta-Espino, J., Herrera-Foessel, S. A., Forrest K. L., Hayden, M. J., and Rebetzke, G. J. 2012. Analysis of leaf and stripe rust severities reveals pathotype changes and multiple minor QTLs associated with resistance in an Avocet×Pastor wheat population. Theor. Appl. Genet. 124: $1283-1294$

Sapkota, S., Hao, Y. F., Johnson, J., Lopez, B., Bland, D., Chen, Z. B., Sutton, S., Buck, J., Youmans, J., and Mergoum, M. 2019. Genetic mapping of a major gene for leaf rust resistance in soft red winter wheat cultivar AGS 2000. Mol. Breed. 39:8.

Shi, X. L., and Ling, H. Q. 2018. Current advances in genome sequencing of common wheat and its ancestral species. Crop J. 6:15-21.

Singh, R. P. 1992. Genetic association of leaf rust resistance gene Lr34 with adult plant resistance to stripe rust in bread wheat. Phytopathology 82:835-838

Singh, R. P., Mujeeb-Kazi, A., and Huerta-Espino, J. 1998. Lr46: A gene conferring slow rusting resistance to leaf rust in wheat. Phytopathology 88: 890-894.

Singh, R. P., and Rajaram, S. 1993. Genetics of adult plant resistance to stripe rust in ten spring bread wheats. Euphytica 72:1-7.

Suchismita, M., Rutkoski, J. E., Govindan, V., Singh, P. K., Crespo-Herrera, L. A., Guzmán, C., Bhavani, S., Lan, C. X., He, Z. H., and Singh, R. P. 2016. Harnessing diversity in wheat to enhance grain yield, climate resilience, disease and insect pest resistance and nutrition through conventional and modern breeding approaches. Front. Plant Sci. 7:991.

Suenaga, K., Singh, R. P., Huerta-Espino, J., and William, H. M. 2003 Microsatellite markers for genes $\mathrm{Lr} 34 / \mathrm{Yr} 18$ and other quantitative trait loci for leaf rust and stripe rust resistance in bread wheat. Phytopathology 93 $881-890$

Thomas, J., Nilmalgoda, S., Hiebert, C., McCallum, B., Humphreys, G., and DePauw, R. 2010. Genetic markers and leaf rust resistance of the wheat gene Lr32. Crop Sci. 50:2310-2317.

Tian, J. C., Deng, Z. Y., Zhang, K. P., Yu, H. X., Jiang, X. L., and Li, C. 2015 Construction of molecular genetic map of wheat. Pages 41-94 in: Genetic Analyses of Wheat and Molecular Marker-Assisted Breeding, Vol. 1. J. C. Tian, Z. Y. Deng, K. P. Zhang, H. X. Yu, X. L. Jiang, and C. Li, eds. Springer, Dordrecht, Netherlands.

Todorovska, E., Christov, N., Slavov, S., Christova, P., and Vassilev, D. 2009 Biotic stress resistance in wheat-breeding and genomic selection implications. Biotechnol. Biotec. Eq. 23:1417-1426.

Van Ooijen, J. W. 2006. Join Map 4, software for the calculation of genetic linkage maps in experimental population. Plant Research International, Wageningen, Netherlands.

Voorrips, R. E. 2002. MapChart: Software for the graphical presentation of linkage maps and QTLs. J. Hered. 93:77-78.

Wang, L., Zheng, D., Zuo, S. X., Chen, X. M., Zhuang, H., Huang, L., Kang, Z. S., and Zhao, J. 2018. Inheritance and linkage of virulence genes in Chinese predominant race CYR32 of the wheat stripe rust pathogen Puccinia striiformis f. sp. tritici. Front. Plant Sci. 9:120.

Wang, M. N., and Chen, X. M. 2017. Stripe rust resistance. Pages 353-558 in: Stripe Rust. X. M. Chen and Z. S. Kang, eds. Springer, Dordrecht, Netherlands.

William, H. M., Singh, R. P., Huerta-Espino, J., Oritiz Islas, S., and Hoisington, D. 2003. Molecular marker mapping of leaf rust resistance gene Lr46 and its association with stripe rust resistance gene Yr29 in wheat. Phytopathology 93:153-159.

William, H. M., Singh, R. P., Huerta-Espino, J., Palacios, G., and Suenaga, K. 2006. Characterization of genetic loci conferring adult plant resistance to leaf rust and stripe rust in spring wheat. Genome 49:977-990.

Wu, J. H., Huang, S., Zeng, Q. D., Liu, S. J., Wang, Q. L., Mu, J. M., Yu, S. Z., Han, D. J., and Kang, Z. S. 2018. Comparative genome-wide mapping versus extreme pool-genotyping and development of diagnostic SNP markers linked to QTL for adult plant resistance to stripe rust in common wheat. Theor. Appl. Genet. 131:1777-1792.

Xing, L. F., Wang, C. F., Xia, X. C., He, Z. H., Chen, W. Q., Liu, T. G., Li, Z. F., and Liu, D. Q. 2014. Molecular mapping of leaf rust resistance gene LrFun in Romanian wheat line Fundulea 900. Mol. Breed. 33:931-937.

Zhang, H., Xia, X. C., He, Z. H., Li, X., Li, Z. F., and Liu, D. Q. 2011. Molecular mapping of leaf rust resistance gene LrBil6 in Chinese wheat cultivar Bimai 16. Mol. Breed. 28:527-534.

Zhang, P. P., Qi, A. Y., Zhou, Y., Xia, X. C., He, Z. H., Li, Z. F., and Liu, D. Q. 2017. Quantitative trait loci mapping of adult-plant resistance to leaf rust in a Fundulea 900x'Thatcher' wheat cross. Plant Breed. 136:1-7.

Zhao, X. L., Zheng, T. C., Xia, X. C., He, Z. H., Liu, D. Q., Yang, W. X., Yin, G. H. and Li, Z. F. 2008. Molecular mapping of leaf rust resistance gene LrZH84 in Chinese wheat line Zhou 8425B. Theor. Appl. Genet. 117:1069-1075. 